\title{
Anti-inflammation activities of essential oil and its constituents from indigenous cinnamon (Cinnamomum osmophloeum) twigs
}

\author{
Yu-Tang Tung ${ }^{a}$, Meng-Thong Chua ${ }^{a}$, Sheng-Yang Wang ${ }^{b}$, Shang-Tzen Chang ${ }^{a, *}$ \\ a School of Forestry and Resource Conservation, National Taiwan University, Taipei 106, Taiwan \\ ${ }^{\mathrm{b}}$ Department of Forestry, National Chung-Hsing University, Taichung 402, Taiwan
}

Received 29 May 2007; received in revised form 27 July 2007; accepted 27 July 2007

Available online 10 September 2007

\begin{abstract}
In this study, chemical compositions of hydrodistilled essential oil and anti-inflammatory activities from the twigs of Cinnamomum osmophloeum Kaneh. were investigated for the first time. The chemical constituents of the twig essential oil were further analyzed by GC-MS and they were found to be L-bornyl acetate $(15.89 \%)$, caryophyllene oxide $(12.98 \%), \gamma$-eudesmol $(8.03 \%)$, $\beta$-caryophyllene $(6.60 \%)$, T-cadinol $(5.49 \%), \delta$-cadinene $(4.79 \%)$, trans- $\beta$-elemenone $(4.25 \%)$, cadalene $(4.19 \%)$, and trans-cinnamaldehyde $(4.07 \%)$. The effects of essential oil on nitric oxide (NO) and prostaglandin $\mathrm{E}_{2}\left(\mathrm{PGE}_{2}\right)$ production in lipopolysaccharide (LPS)-activated RAW 264.7 macrophages were also examined. Results of nitric oxide tests indicated that twig essential oil and its major constituents such as trans-cinnamaldehyde, caryophyllene oxide, L-borneol, L-bornyl acetate, eugenol, $\beta$-caryophyllene, $E$-nerolidol, and cinnamyl acetate have excellent activities. These findings demonstrated that essential oil of $C$. osmophloeum twigs have excellent anti-inflammatory activities and thus have great potential to be used as a source for natural health products.
\end{abstract}

(C) 2007 Elsevier Ltd. All rights reserved.

Keywords: Cinnamomum osmophloeum; Twigs; Essential oil; trans-Cinnamaldehyde; Anti-inflammation

\section{Introduction}

Inflammatory response protects the host against tissue injury and microbial invasion. As such, this response should be short-lived, and failing can result in pathogenesis of many immunity-related diseases (Pulendran et al., 2001; Steinman, 2004). Today the treatment of inflammatory diseases involves mainly interrupting the synthesis or action of critical mediators that drive the host's response to injury. Although steroids and antihistamines have provided the main treatment for inflammatory diseases, they exist for the treatment of inflammation-driven diseases such as asthma, rheumatoid arthritis, psoriatic arthritis, systemic lupus erythematosus, Crohn's disease, multiple sclerosis, and systemic vasculitis (Gayathri et al., 2007). An alternative approach to the development of novel therapeutics

\footnotetext{
${ }^{*}$ Corresponding author. Tel.: +88623366 4626; fax: +886223654520. E-mail address: peter@ntu.edu.tw (S.-T. Chang).
}

involving the endogenous mediators and mechanisms that switch off inflammation is being carried out in this study and it is thought that this strategy will bring in new possibilities for the future management of inflammation-based diseases.

Cinnamomum osmophloeum Kaneh. (Lauraceae) is an endemic tree that grows in natural hardwood forest of Taiwan at an elevation between 400 and $1500 \mathrm{~m}$. This tree species has been of interested to researchers because the chemical constituents of its essential oil are similar to those of Cinnamomum cassia bark oil, known as cinnamon oil, which is commonly used in food and beverages (Ooi et al., 2006). Recent phytochemical analyses and biological screenings of $C$. osmophloeum have focused on the leaf essential oil components, which has shown excellent inhibitory effects on anti-bacteria, anti-termites, anti-mites, antimildew, anti-mosquito larvae, and anti-fungi (Chang et al., 2001; Chang and Cheng, 2002; Chen et al., 2002; Chen and Chang, 2002; Cheng et al., 2004, 2006). Furthermore, Chao 
et al. (2005) reported that essential oil of C. osmophloeum leaves at a dose of $60 \mu \mathrm{g} / \mathrm{ml}$ also exhibited effective inhibitory effects on IL-1 $\beta$ and IL-6 productions in LPSstimulated macrophages. However, to the best of our knowledge, there is no prior study on the essential oil of C. osmophloeum twigs. In this study, chemical compositions of hydrodistilled essential oil obtained from C. osmophloeum twigs were analyzed by gas chromatography-mass spectrometry (GC-MS), and the effects of essential oil on nitric oxide $(\mathrm{NO})$ and prostaglandin $\mathrm{E}_{2}\left(\mathrm{PGE}_{2}\right)$ production in lipopolysaccharide (LPS)-activated RAW 264.7 macrophages were investigated. In addition, the cytotoxicity of essential oil against human hepatoma cancer cell line, HepG2 cells, was also examined.

\section{Methods}

\subsection{Plant material}

The twigs of a 13-year-old C. osmophloeum Kaneh. were collected at the end of July 2004 from the Taiwan Sugar Company Research Center located in Nantou County in central Taiwan. Diameter of the twigs selected was below $1.5 \mathrm{~cm}$. The species was confirmed by Dr.Yen-Ray Hsui of the Taiwan Forestry Research Institute and voucher specimens were deposited at the laboratory of wood chemistry (School of Forestry and Resource Conservation, National Taiwan University).

\subsection{Essential oil distillation}

Twigs of C. osmophloeum, in triplicate, were subjected to hydrodistillation for $6 \mathrm{~h}$ in a Clevenger-type apparatus (Chang et al., 2001). The yellow-colored essential oil with characteristic odor was obtained and stored in airtight containers prior to further analysis.

\subsection{Analysis of essential oil}

Essential oil from twigs was analyzed by a PolarisQ Ion Trap GC/FID/MS ${ }^{\mathrm{n}}$ system (Themo, USA), equipped with a $30 \mathrm{~m} \times 0.25 \mathrm{~mm} \times 0.25 \mu \mathrm{m}$ DB-5MS (Agilent J\&W Scientific). The $\mathrm{GC}$ oven temperature was programmed from $80{ }^{\circ} \mathrm{C}$, held $1 \mathrm{~min}$, raised to $200{ }^{\circ} \mathrm{C}$ at $4{ }^{\circ} \mathrm{C} / \mathrm{min}$, and held for $5 \mathrm{~min}$. The injector temperature was $250^{\circ} \mathrm{C}$; and the flow rate of carrier gas, helium, was at $1.0 \mathrm{ml} / \mathrm{min} ; 1: 10$ split ratio. Diluted samples $(1.0 \mu 1,1 / 100, v / v$, in ethyl acetate) were injected manually in the split mode. The Kovats indices were calculated for all volatile constituents using a homologous series of $n$-alkanes $\mathrm{C}_{9}-\mathrm{C}_{25}$ on DB-5MS column. The major components of C. osmophloeum twig oil were identified by co-injection with standards (wherever possible), confirmed with Kovats indices using the Wiley (V. 7.0) and National Institute of Standards and Technology (NIST) V.2.0 GC-MS library. The relative concentration of each compound in essential oil was quantified based on the peak area integrated by the analysis program.

\subsection{Chemicals}

Lipopolysaccharide (LPS), Greiss reagent, $\beta$-caryophyllene, and 3-(4,5-dimethylthiazol-2-yl)-2,5-diphenyl tetrazolium bromide (MTT) were purchased from Sigma Chemical Co. (St. Louis, MO). Quercetin, L-borneol, $\alpha-$ terpineol, $p$-allylanisole, trans-cinnamaldehyde, L-bornyl acetate, eugenol, cinnamyl acetate, $E$-nerolidol, caryophyllene oxide, and methyl sulfoxide (DMSO) were all purchased by Acros (Belgium). PGE $_{2}$ enzyme inmmunoassay kit was purchased from EIA, Cayman Chemical (USA). Dulbecco's modified eagle medium (DMEM) was purchased from Gibco BRL (USA).

\subsection{Cell line and cell culture}

RAW 264.7 cells, a murine macrophage cell line and HepG2 cells, a human hepatocellular liver carcinoma cell line were obtained from the Culture Collection and Research Center (CCRC), Hsinchu, Taiwan. Cells were cultured in 75- or $150-\mathrm{cm}^{2}$ flasks with Dulbecco's modified eagle medium (DMEM) supplemented with 10\% fetal bovine serum (FBS), $100 \mathrm{U} / \mathrm{ml}$ penicillin, and $100 \mu \mathrm{g} / \mathrm{ml}$ streptomycin. Cells were incubated in a $5 \% \mathrm{CO}_{2}$ incubator at $37^{\circ} \mathrm{C}$.

\subsection{Cytotoxicity assay on tumor cells (MTT assay)}

This assay was performed according to the procedure reported by Mossmann (1983) with slight modifications. To measure the cytotoxicity of essential oil, caryophyllene oxide, and L-bornyl acetate in cell proliferation, the HepG2 cells $\left(1 \times 10^{4}\right.$ cells/well $)$ were seeded into a 96-well plate in triplicate and pre-incubated for $3 \mathrm{~h}$ for cell adherence. First, $100 \mu \mathrm{l}$ of fresh medium containing various concentrations of test samples were added into the cultures and incubated at $37^{\circ} \mathrm{C}$ for $72 \mathrm{~h}$ under humidified air containing $5 \%$ $\mathrm{CO}_{2}$. Following the removal of the medium from the wells, $100 \mu \mathrm{l}$ of tetrazolium salt solutions ( $1 \mathrm{ml}$ MTT in $10 \mathrm{ml}$ DMEM) were added. After $4 \mathrm{~h}$ of incubation at $37^{\circ} \mathrm{C}$, the medium was removed and $100 \mu \mathrm{l}$ of DMSO were added to dissolve the formazan crystals. Absorbance was measured in an enzyme-linked immunosorbent assay (ELISA) reader at $570 \mathrm{~nm}$. The cell viability ratio (\%) was calculated from the following equation: $\%$ viability $=($ absorbance of test sample/absorbance of control) $\times 100$.

\subsection{Anti-inflammatory activity assay}

To investigate the anti-inflammatory activity of $C$. osmophloeum twig essential oils, $\mathrm{NO}$ and $\mathrm{PGE}_{2}$ productions in LPS-stimulated RAW 264.7 cells were examined. For NO determination, RAW 246.7 cells were seeded in 96-well plates at a density of $2 \times 10^{5}$ cells/well and grown for $2 \mathrm{~h}$ for adherence. The cells were treated with test samples for $1 \mathrm{~h}$ and then incubated for $24 \mathrm{~h}$ in fresh DMEM with or without $1 \mu \mathrm{g} / \mathrm{ml}$ of LPS. The nitrite concentration 
in the culture medium was measured as an indicator of NO production according to the Griess reaction (Kim et al., 1999). Briefly, $100 \mu 1$ of cell culture supernatant were reacted with $100 \mu \mathrm{l}$ of Griess reagent (1:1 mixture of $0.1 \%$ $N$-(1-naphthyl) ethylene-diamine dihydrochloride in water and $1 \%$ sulfanilamide in $5 \%$ phosphoric acid) in a 96-well plate, and absorbance at $540 \mathrm{~nm}$ was recorded using the ELISA reader.

For $\mathrm{PGE}_{2}$ determination, RAW 264.7 cells were seeded in 96-well plates at a density of $1 \times 10^{4}$ cells/well and incubated for $18 \mathrm{~h}$. Cells were pretreated with $500 \mu \mathrm{M}$ of aspirin for $3 \mathrm{~h}$ to inactivate endogenous cyclooxygenase-1 (COX-1) according to the method reported by Hwang et al. (2002). Then, cells were washed twice with phosphate buffered saline (PBS) and further incubated for $16 \mathrm{~h}$ in fresh DMEM with or without $1 \mu \mathrm{g} / \mathrm{ml}$ of LPS in the absence or presence of the test samples. After incubation, supernatants were collected to measure $\mathrm{PGE}_{2}$ concentration with monoclonal antibody by ELISA as specified by the manufacturer.

\subsection{Cell viability}

The cell viability assay was determined on the basis of MTT assay as described above with a slight modification. After culture, supernatants were collected for NO or $\mathrm{PGE}_{2}$ measurement, $100 \mu \mathrm{l}$ of tetrazolium salt solutions $(1 \mathrm{ml}$ MTT in $10 \mathrm{ml}$ DMEM) were added to each well, and then incubated for $1 \mathrm{~h}$ at $37^{\circ} \mathrm{C}$ in a $5 \% \mathrm{CO}_{2}$ incubator. The medium was then aspirated, and the insoluble formazan product was dissolved in $100 \mu 1$ of DMSO. The extent of MTT reduction was quantified by measuring the absorbance at $570 \mathrm{~nm}$.

\subsection{Statistical analysis}

All results are expressed as mean $\pm \mathrm{SD}(n=3)$. The significance of difference was calculated by SAS Scheffe's test, and values $<0.05$ were considered to be significant.

\section{Results and discussion}

\subsection{Yield and constituents of essential oil}

Hydrodistillation of C. osmophloeum twigs yields $0.08 \%$ (w/w) essential oil according to dry weight. Compared with the yields of essential oils from C. osmophloeum leaves, ranging from $0.1 \%$ to $2.9 \%$ (Cheng et al., 2006), the yield of essential oil from C. osmophloeum twigs was lower. A total of 24 compounds (Table 1) were identified in the twig essential oil, representing $97.62 \%$ of the total essential oil. The main constituents in twig essential oil were quantified to be L-bornyl acetate $(15.89 \%)$, caryophyllene oxide $(12.98 \%), \gamma$-eudesmol $(8.03 \%), \beta$-caryophyllene $(6.60 \%)$, T-cadinol $(5.49 \%), \delta$-cadinene $(4.79 \%)$, trans- $\beta$-elemenone $(4.25 \%)$, cadalene $(4.19 \%)$, and trans-cinnamaldehyde $(4.07 \%)$ according to the results obtained from GC-MS and GC-FID analyses. Although the constituents of the leaf oil can be classified into different chemotypes according to their contents, most of the constituents are monoterpenes or belong to other groups, such as camphor, linalool, trans-cinnamaldehyde, and cinnamyl acetate (Cheng et al., 2006). On the other hand, in the twig essential oil, most of the constituents are sesquiterpenes. In this study, $35.63 \%$ of the constituents were identified as oxygenated sesquiterpene, followed by sesquiterpene hydrocarbons (29.31\%), oxygenated monoterpene $(23.15 \%)$, and others $(9.53 \%)$.

\subsection{Effects of essential oil on cytotoxicity of HepG2 cells}

Hepatocellular carcinoma is one of the most common malignancies worldwide. The high incidence of liver cancer has been attributed to factors such as persistent infection with hepatitis virus and contact with hepatocarcinogens such as nitrosamines and aflatoxins (Henry et al., 2002). The cytotoxic effects of $C$. osmophloeum twig essential oil and its main components (L-bornyl acetate and caryophyllene oxide) were investigated using a MTT assay on HepG2 cells, a hepatoma liver cancer cell line. A mitochondrial enzyme in living cells, succinate-dehydrogenase, cleaves the tetrazolium ring, converting the MTT to an insoluble purple formazan. Therefore, the amount of formazan produced is directly proportional to the number of viable cells (Mossmann, 1983). At the dosage of $250 \mu \mathrm{g} / \mathrm{ml}$, essential oil of C. osmophloeum twigs exhibited excellent inhibitory effects only with $36.6 \%$ of cells survived. However, no significant inhibition effects on cell survival were observed for both caryophyllene oxide and L-bornyl acetate, which are two major constituents in the twig essential oil (data were not shown).

\subsection{Effects of essential oil and its constituents on NO production in LPS-stimulated RAW 264.7 cells}

NO is an endogenous free radical species that is synthesized from L-arginine by nitric oxide synthase (NOS) in various animal cells and tissues. Small amounts of NO are important regulators of physical homeostasis, whereas large amounts of NO have been closely correlated with the pathophysiology of a variety of diseases and inflammation. After exposure to inducers, such as lipopolysaccharide (LPS) from Gram-negative bacteria, inducible NOS (iNOS) can be induced in various cells, such as macrophages, kupffer cells, smooth muscle cells, and hepatocytes, to trigger cytotoxicity, tissue damage, inflammation sepsis, and stroke (Marletta, 1993; Jiang et al., 2006). Thus, measuring of NO production may be a method for assessing the anti-inflammatory effects of plant extracts.

As for the inhibitory effects of $C$. osmophloeum twig essential oil on NO productions, data in Fig. 1 show that essential oil of $C$. osmophloeum twigs had the excellent inhibitory effect. In the presence of $25 \mu \mathrm{g} / \mathrm{ml}$ of essential oil, the inhibition of NO production was $68.8 \%$. The $\mathrm{IC}_{50}$ value was $11.2 \mu \mathrm{g} / \mathrm{ml}$. In addition, MTT assay revealed 
Table 1

Yields and composition of essential oil from C. osmophloeum twigs

\begin{tabular}{|c|c|c|c|c|c|}
\hline No. & Constituents & R.t. $^{a}$ & $\mathrm{KI}^{\mathrm{b}}$ & Area $(\%)$ & Identification $^{c}$ \\
\hline 1 & L-Borneol & 8.55 & 1172 & 1.34 & MS, KI \\
\hline 2 & $\alpha$-Terpineol & 9.19 & 1194 & 1.67 & MS, KI \\
\hline 3 & $p$-Allylanisole & 9.36 & 1199 & 2.45 & MS, KI \\
\hline 5 & L-Bornyl acetate & 11.40 & 1289 & 15.89 & MS, KI, ST \\
\hline 6 & Eugenol & 14.01 & 1360 & 0.95 & MS, KI \\
\hline 7 & $\alpha$-Copaene & 14.70 & 1382 & 3.93 & MS, KI \\
\hline 10 & $\alpha$-Caryophyllene & 17.02 & 1460 & 1.43 & MS, KI \\
\hline 11 & Curcumene & 17.80 & 1486 & 1.67 & MS, KI \\
\hline 12 & $\delta$-Cadinene & 19.03 & 1528 & 4.79 & MS, KI \\
\hline 13 & $\alpha$-Calacorene & 19.59 & 1548 & 1.88 & MS, KI \\
\hline 14 & Elemicin & 19.88 & 1558 & 0.85 & MS, KI \\
\hline 15 & $E$-Nerolidol & 20.13 & 1566 & 1.05 & MS, KI \\
\hline 20 & $\gamma$-Eudesmol & 22.02 & 1633 & 8.03 & MS, KI \\
\hline 21 & Caryophylla-4(14), 8(15)-dien-5.alpha-ol & 22.25 & 1641 & 3.74 & MS, KI \\
\hline 22 & $\delta$-Cadinol & 22.39 & 1646 & 3.51 & MS, KI \\
\hline 23 & T-Cadinol & 22.75 & 1659 & 5.49 & MS, KI \\
\hline 24 & Cadalene & 23.21 & 1676 & 4.19 & MS, KI \\
\hline 25 & Guaiol acetate & 24.53 & 1720 & 1.37 & MS, KI \\
\hline \multicolumn{4}{|c|}{ Oxygenated monoterpene identified (\%) } & 23.15 & \\
\hline \multicolumn{4}{|c|}{ Sesquiterpene hydrocarbons identified (\%) } & 29.31 & \\
\hline \multicolumn{4}{|c|}{ Oxygenated sesquiterpene identified (\%) } & 35.63 & \\
\hline \multicolumn{4}{|c|}{ Other $(\%)$} & 9.53 & \\
\hline \multicolumn{4}{|c|}{ Identified components $(\%)$} & 97.62 & \\
\hline \multicolumn{4}{|c|}{ Oil yield $(\%, w / w t)$} & $0.08 \pm 0.01$ & \\
\hline
\end{tabular}

\footnotetext{
${ }^{\mathrm{a}}$ Retention time (min).

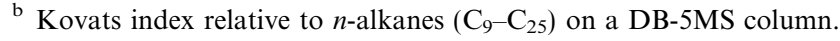

${ }^{\mathrm{c}}$ Identification based on comparison of the mass spectrum, Kovats index on a DB-5MS column in reference (Adams, 2001) and co-injection with authentic compounds.
}

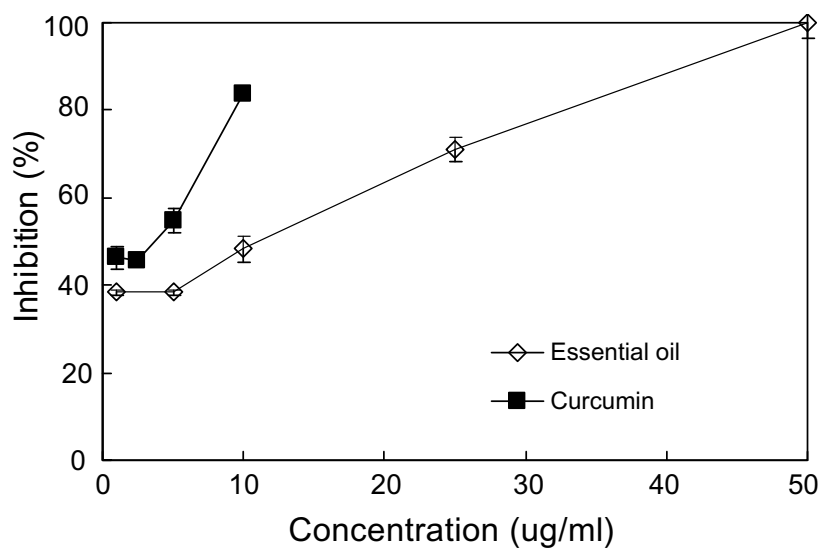

Fig. 1. Effects of essential oil from C. osmophloeum twigs and curcumin on nitric oxide production of LPS-stimulated RAW 264.7 macrophage cells. Results are mean $\pm \mathrm{SD}(n=3)$.

that concentrations up to $50 \mu \mathrm{g} / \mathrm{ml}$ produced no significant cytotoxic effects on cells treated with essential oil. According to the results reported by Lee et al. (2002), Cinnamomum cassia extract was found to possess significant inhibition of $\mathrm{NO}$ production, with an $\mathrm{IC}_{50}$ value is between 1 and $5 \mu \mathrm{g} / \mathrm{ml}$. The result indicates that essential oil of $C$. osmophloeum twig has a good performance of inhibiting NO production. To understand the relationship between the constituents of $C$. osmophloeum twig essential oil and NO production inhibitory effects in RAW 264.7 macrophages, 10 constituents, namely L-borneol, $\alpha$-terpineol, $p$ allylanisole, trans-cinnamaldehyde, L-bornyl acetate, eugenol, $\beta$-caryophyllene, cinnamyl acetate, $E$-nerolidol, and caryophyllene oxide were tested. Curcumin, a well known for its anti-inflammatory activity, was used in parallel as a positive control. trans-Cinnamaldehyde $(59.9 \%)$ and caryophyllene oxide (54.0\%) exhibited better NO inhibition effects than twig essential oil $(48.3 \%)$ at the concentration of $10 \mu \mathrm{g} / \mathrm{ml}$; while L-borneol (46.1\%), L-bornyl acetate (45.7\%), eugenol (46.2\%), $\beta$-caryophyllene $(50.9 \%), E$-nerolidol $(40.7 \%)$, cinnamyl acetate $(48.1 \%)$ showed activity similar to that of twig essential oil. Nevertheless, $\alpha$-terpineol $(38.1 \%)$ and $p$-allylanisole $(30.9 \%)$ were found to be the least active. In addition, MTT assay revealed no significant cytotoxic effects on cells treated with the 10 constituents at the dosage of $10 \mu \mathrm{g} / \mathrm{ml}$. 

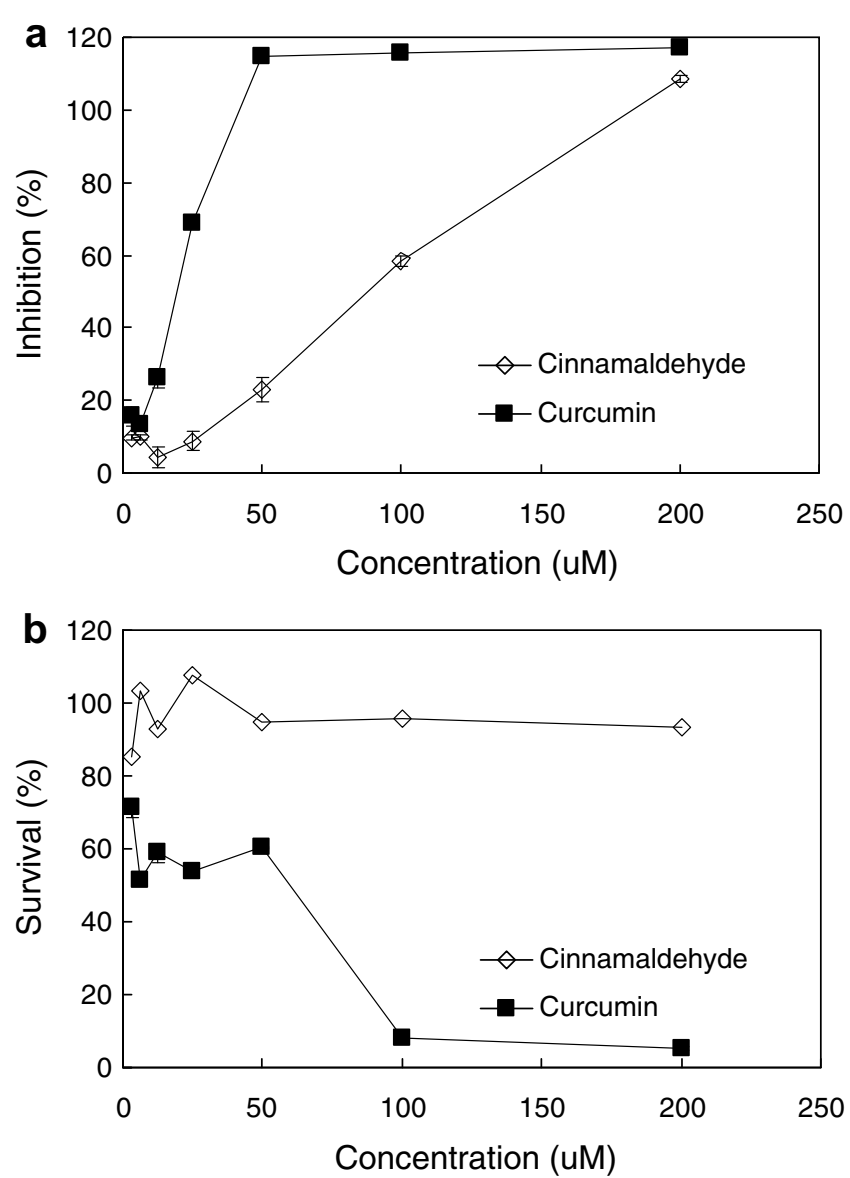

Fig. 2. Effects of trans-cinnamaldehyde and curcumin on nitric oxide production of LPS-stimulated RAW 264.7 macrophage cells. (a) represents the concentration-dependent inhibition of nitric oxide production and (b) indicates the cytotoxicty of pure compound on RAW 264.7 cells in the presence of LPS, measured by the MTT assay. Results are mean \pm SD $(n=3)$.

Amongst the 10 compounds tested, trans-cinnamaldehyde exhibited the strongest activity. To examine further the inhibition of NO generation in LPS-stimulated RAW 264.7 cells, we selected different doses of trans-cinnamaldehyde. Fig. 2a shows that trans-cinnamaldehyde inhibited LPS-induced NO production in a concentration-dependent manner, with the $\mathrm{IC}_{50}$ value being $88.4 \mu \mathrm{M}$. Furthermore, at the dosage of $200 \mu \mathrm{M}$, the inhibition of NO production by trans-cinnamaldehyde was $100.8 \%$. In addition, MTT assay revealed no significant cytotoxic effects on cells treated with trans-cinnamaldehyde at concentrations up to $200 \mu \mathrm{M}$ (Fig. 2b). Lee et al. (2002) have also proved that trans-cinnamaldehyde has strong activity on suppressing NO synthase. Thus, trans-cinnamaldehyde might be a potential lead compound for the development of antiinflammatory drugs.

\subsection{Effects of essential oil and its constituents on $P G E_{2}$ production in LPS-stimulated RAW 264.7 cells}

The activation of macrophages plays a critical role in the inflammatory process by releasing a variety of inflamma- tory mediators (Hwang et al., 2002). Besides NO production, $\mathrm{PGE}_{2}$ was also an important inflammatory mediator involved in the pathogenesis (Surh et al., 2001). Thus, in addition to measuring NO productions, determining the inhibitory effects on the abnormal accumulation of $\mathrm{PGE}_{2}$ was another method by which the anti-inflammatory effects of plant extracts can be assessed.

After induction of LPS, the accumulation of $\mathrm{PGE}_{2}$ in RAW 264.7 cells increased from 72.7 to $655.6 \mathrm{pg} / \mathrm{ml}$. However, indomethacin, the positive control and essential oil of C. osmophloeum twigs inhibited the LPS-induced accumulation of $\mathrm{PGE}_{2}$ in a concentration-dependent manner. At a concentration of $10 \mu \mathrm{g} / \mathrm{ml}$, essential oil of C. osmophloeum twigs significantly decreased almost $65 \%$ of the $\mathrm{PGE}_{2}$ production in LPS-induced RAW 264.7 cells, while indomethacin exhibited $98 \%$ inhibition of $\mathrm{PGE}_{2}$ production. At a concentration of $25 \mu \mathrm{g} / \mathrm{ml}$, caryophyllene oxide and L-bornyl acetate decreased almost $18 \%$ and $28 \%$ of the $\mathrm{PGE}_{2}$ production. The result reveals no significant inhibition effects of $\mathrm{PGE}_{2}$ were observed for caryophyllene oxide and L-bornyl acetate, which are two major constituents in the twig essential oil.

In the anti-inflammatory assay, essential oil of C. osmophloeum twigs showed excellent inhibitory effects on $\mathrm{PGE}_{2}$, but unfortunately, major constituents such as caryophyllene oxide and L-bornyl acetate, were not responsible for suppressing $\mathrm{PGE}_{2}$ production. Our findings suggested that the excellent performance of twig essential oil might be attributable to the effects of minor constituents or synergetic effects among the constituents. To find out the key elements responsible for suppressing $\mathrm{PGE}_{2}$ production and to clarify the mechanisms involved, further investigations are warranted.

\section{Conclusion}

This study demonstrated that essential oil of C. osmophloeum twigs has excellent anti-inflammatory activities and cytotoxicity against HepG2 cells. Furthermore, it also indicated that the constituents of C. osmophloeum twig essential oil such as trans-cinnamaldehyde, caryophyllene oxide, L-borneol, L-bornyl acetate, eugenol, $\beta$-caryophyllene, $E$-nerolidol, and cinnamyl acetate exhibited excellent anti-inflammatory activities in suppressing nitric oxide production by LPS-stimulated macrophages. The essential oil of C. osmophloeum twigs is worthy for further investigation, due to its excellent performance found in this study.

\section{Acknowledgement}

We thank the Forestry Bureau of Council of Agriculture for the financial support.

\section{References}

Adams, R.P., 2001. Identification of essential oil components by gas chromatography/quadrupole mass spectroscopy. Allured, Illinois. 
Chang, S.T., Cheng, S.S., 2002. Antitermitic activity of leaf essential oils and components from Cinnamomum osmophloeum. J. Agric. Food Chem. 50, 1389-1392.

Chang, S.T., Chen, P.F., Chang, S.C., 2001. Antibacterial activity of leaf essential oils and components from Cinnamomum osmophloeum. J. Ethnopharmacol. 77, 123-127.

Chao, L.K., Hua, K.F., Hsu, H.Y., Cheng, S.S., Liu, J.Y., Chang, S.T., 2005. Study on the anti-inflammatory activity of essential oil from leaves of Cinnamomum osmophloeum. J. Agric. Food Chem. 53, 7274 7278.

Chen, P.F., Chang, S.T., 2002. Application of essential oils from wood on the manufacture of environment-friendly antimicrobial paper products. Quart. J. Chin. For. 35, 69-74.

Chen, P.F., Chang, S.T., Wu, H.H., 2002. Antimite activity of essential oils and their components from Cinnamomum osmophloeum. Quart. J. Chin. For. 35, 397-404.

Cheng, S.S., Liu, J.Y., Tsai, K.H., Chen, W.J., Chang, S.T., 2004. Chemical composition and mosquito larvicidal activity of essential oils from leaves of different Cinnamomum osmophloeum provenances. J. Agric. Food Chem. 52, 4395-4400.

Cheng, S.S., Liu, J.Y., Hsui, Y.R., Chang, S.T., 2006. Chemical polymorphism and antifungal activity of essential oils from leaves of different provenances of indigenous cinnamom (Cinnamomum osmophloeum). Bioresour. Technol. 97, 306-312.

Gayathri, B., Manjula, N., Vinaykumar, K.S., Lakshmi, B.S., Balakrishnan, A., 2007. Pure compound from Boswellia serrata extract exhibits anti-inflammatory property in human PBMCs and mouse macrophages through inhibition of TNF $\alpha, \mathrm{IL}-1 \beta, \mathrm{NO}$ and MAP kinases. Int. Immunopharmacol. 7, 473-482.

Henry, S.H., Bosch, F.X., Bowers, J.C., 2002. Aflatoxin, hepatitis and worldwide liver cancer risks. Adv. Exp. Med. Biol. 504, 229-233.

Hwang, B.Y., Lee, J.H., Koo, T.H., Kim, H.S., Hong, Y.S., Ro, J.S., Lee, K.S., Lee, J.J., 2002. Furanoligularenone, an eremophilane from
Ligularia fischeri, inhibits the LPS-induced production of nitric oxide and prostaglandin $\mathrm{E}_{2}$ in macrophage RAW 264.7 cells. Planta Med. 68, 101-105.

Jiang, J.S., Shih, C.M., Wang, S.H., Chen, T.T., Lin, C.N., Ko, W.C., 2006. Mechanisms of suppression of nitric oxide production by $3-O$ methylquercetin in RAW 264.7 cells. J. Ethnopharmacol. 103, 281287.

Kim, H.K., Cheon, B.S., Kim, Y.H., Kim, S.Y., Kim, H.P., 1999. Effects of naturally flavonoids on nitric oxide production in the macrophage cell line RAW 264.7 and their structure-activity relationships. Biochem. Pharmacol. 58, 759-765.

Lee, H.S., Kim, B.S., Kim, M.K., 2002. Suppression effect of Cinnamomum cassia bark-derived component on nitric oxide synthase. J. Agric. Food Chem. 50, 7700-7703.

Marletta, M.A., 1993. Nitric oxide synthase structure and mechanism. J. Biol. Chem. 268, 12231-12234.

Mossmann, T., 1983. Rapid colorimetric assay for cellular growth and survival: application to proliferation and cytotoxicity assays. J. Immunol. Meth. 65, 55-63.

Ooi, L.S., Li, Y., Kam, S.L., Wang, H., Wong, E.Y., Ooi, V.E., 2006. Antimicrobial activities of cinnamon oil and cinnamaldehyde from the Chinese medicinal herb Cinnamomum cassia. Blume. Am. J. Chin. Med. 34, 511-522.

Pulendran, B., Palucka, K., Banchereau, J., 2001. Sensing pathogens and tuning immune responses. Science 293, 253-256.

Steinman, L., 2004. Immune therapy for autoimmune diseases. Science 305, 212-216.

Surh, Y.J., Chun, K.S., Cha, H.H., Han, S.S., Keum, Y.S., Park, K.K., Lee, S.S., 2001. Molecular mechanisms underlying chemopreventive activities of anti-inflammatory phytochemicals: down-regulation of COX-2 and iNOS through suppression of NF- $k B$ activation. Mutat. Res., 243-268. 